\title{
Anti-IL-5 treatment reduces deposition of ECM proteins in the bronchial subepithelial basement membrane of mild atopic asthmatics
}

\author{
Patrick Flood-Page, ${ }^{1}$ Andrew Menzies-Gow, ${ }^{1}$ Simon Phipps, ${ }^{1}$ Sun Ying, ${ }^{2}$ Arun Wangoo, ${ }^{1}$ \\ Mara S. Ludwig, ${ }^{3}$ Neil Barnes, ${ }^{4}$ Douglas Robinson, ${ }^{1}$ and A. Barry Kay ${ }^{1}$ \\ ${ }^{1}$ Department of Allergy and Clinical Immunology, Imperial College London, National Heart and Lung Institute, \\ London, United Kingdom \\ 2Division of Asthma, Allergy and Lung Biology, Guy's, King's and St. Thomas' School of Medicine, Guy's Hospital, \\ London, United Kingdom \\ ${ }^{3}$ Meakins Christie Laboratories, McGill University Hospital Center, Montreal, Quebec, Canada \\ ${ }^{4}$ Department of Respiratory Medicine, Barts and the Royal London Hospitals Trust, London, United Kingdom
}

\begin{abstract}
Eosinophil-derived TGF- $\beta$ has been implicated in remodeling events in asthma. We hypothesized that reduction of bronchial mucosal eosinophils with anti-IL-5 would reduce markers of airway remodeling. Bronchial biopsies were obtained before and after three infusions of a humanized, anti-IL-5 monoclonal antibody (mepolizumab) in 24 atopic asthmatics in a randomized, double-blind, placebo-controlled study. The thickness and density of tenascin, lumican, and procollagen III in the reticular basement membrane (RBM) were quantified immunohistochemically by confocal microscopy. Expression of TGF- $\beta 1$ mRNA by airway eosinophils was assessed by in situ hybridization, and TGF- $\beta 1$ protein was measured in bronchoalveolar lavage (BAL) fluid by ELISA. At baseline, airway eosinophil infiltration and ECM protein deposition was increased in the RBM of asthmatics compared with nonasthmatic controls. Treating asthmatics with anti-IL-5 antibody, which specifically decreased airway eosinophil numbers, significantly reduced the expression of tenascin, lumican, and procollagen III in the bronchial mucosal RBM when compared with placebo. In addition, anti-IL-5 treatment was associated with a significant reduction in the numbers and percentage of airway eosinophils expressing mRNA for TGF- $\beta 1$ and the concentration of TGF- $\beta 1$ in BAL fluid. Therefore eosinophils may contribute to tissue remodeling processes in asthma by regulating the deposition of ECM proteins.
\end{abstract}

J. Clin. Invest. 112:1029-1036 (2003). doi:10.1172/JCI200317974.

\section{Introduction}

Allergic asthma is characterized by eosinophilic airway inflammation and structural changes in the airway wall termed remodeling (1). This remodeled phenotype, which may be the consequence of excessive repair processes following repeated airway injury, includes increased deposition of ECM proteins in the reticular basement membrane (RBM) (2) and in the bronchial submucosa (3). These ECM proteins include procollagen III (the mature precursor for collagen III) and the proteoglycans, tenascin, and lumican $(2,4-6)$. In addition to their structural role, ECM

Received for publication January 27, 2003, and accepted in revised form August 5, 2003.

Address correspondence to: A. Barry Kay, Department of Allergy and Clinical Immunology,

Imperial College London, National Heart and Lung Institute,

Dovehouse Street, London SW3 6LY, United Kingdom.

Phone: 44-207-351-8181; Fax: 44-201-376 3138;

E-mail: a.b.kay@imperial.ac.uk.

Conflict of interest: The authors have declared that no conflict of interest exists.

Nonstandard abbreviations used: reticular basement membrane (RBM); bronchoalveolar lavage (BAL); forced expiratory volume (FEV); peak expiratory flow rate (PEFR); major basic protein (MBP); alkaline phosphatase antialkaline phosphatase (APAAP); in situ hybridization (ISH); airways hyperreactivity (AHR). proteins may also influence cellular function including adhesion, differentiation, and survival $(7,8)$. Other features of remodeling include increased smooth muscle mass (9), goblet cell hyperplasia (10), and new blood vessel formation (11).

There is increasing evidence that the eosinophil may be important in the pathophysiology of airways remodeling. For example, thickening of the subepithelial basement membrane was associated with increases in bronchial mucosal eosinophils in severe asthmatics (12). Tissue eosinophilia and eosinophil degranulation have been associated with several fibrotic syndromes (13-15), and the cell is a source of several molecules implicated in tissue remodeling processes such as TGF- $\alpha$ (16), TGF- $\beta$ (17), VEGF (18), matrix metalloperoxidase9 (19), tissue inhibitor of metalloproteinase-1 (20), and IL-13 (21). TGF- $\beta$ is a potent regulator of fibroblast/myofibroblast function with the production of several ECM proteins including collagens, proteoglycans, and tenascin $(22,23)$.

Our group reported that eosinophil-derived TGF- $\beta 1$ is temporally associated with myofibroblast formation and the expression of tenascin and procollagen-I by fibroblasts in allergic inflammation in vivo in human atopic skin (24). Direct evidence for the production of these repair markers was obtained in vitro by coculturing 
eosinophils and fibroblasts. In addition, eosinophilinduced myofibroblast formation was associated with the generation of tenascin transcripts and protein product, which was could be inhibited by neutralizing antibodies to TGF- $\beta$. Interleukin- 5 is essential for the terminal differentiation of the committed eosinophil precursor (25). It is also involved in eosinophil migration and priming (26) and prolongs the survival of the cell in tissues (27). More recently, monoclonal antibodies to IL-5 have been prepared and administered as a single intravenous infusion to both mild atopic (28) and chronic, severe asthmatics (29). These antibodies have produced no appreciable effects on late asthmatic reaction, airway hyperresponsiveness, or other clinical outcomes including lung function. However, although anti-IL-5 almost totally ablated eosinophils in the blood and sputum (28), tissue eosinophils were reduced rather than depleted (30), possibly as a result of downregulated IL-5R $\alpha$ expression of airway eosinophils $(31,32)$. Our own group has been able to partially and selectively deplete eosinophils from the airway mucosa of mild atopic asthmatics using three intravenous infusions of an anti-IL-5 monoclonal antibody given at monthly intervals (30). In the present study, we have used these biopsy samples to show that, even with the modest reduction in bronchial mucosal eosinophils achieved (median decrease of $55 \%$ ), this was associated with significant decreases in the deposition of the ECM proteins within the reticular basement membrane.

\section{Methods}

\section{Study population and design}

Normal nonatopic human volunteers were recruited by advertisement. The asthmatics were part of a study that has been described in detail elsewhere (30). Briefly, 24 mild atopic asthmatic volunteers, treated only with $\beta_{2}$ agonists as required, completed the study. Eleven were randomized to receive mepolizumab and 11 , placebo. Both groups were well matched in terms of age, sex, forced expiratory volume $\left(\mathrm{FEV}_{1}\right)$, peak expiratory flow rate (PEFR), and histamine $\mathrm{PC}_{20}$.

Seven to 14 days after screening, fiberoptic bronchoscopy with endobronchial biopsy and bronchoalveolar lavage (BAL) were performed, and 2 days later the study medication (placebo or active drug) was given. This was administered as an intravenous infusion over 30 minutes in a double-blind fashion. The second and third infusions of study drug were given 4 and 8 weeks following the first infusion. Bronchoscopy was repeated 2 weeks after the final drug infusion.

Bronchial mucosal biopsies were taken from lowerlobe segmental and subsegmental carinae. Whether the pretreatment biopsies were taken from the right or left side was determined randomly. The post-treatment biopsies were then taken from the other side. Bronchial biopsies were also taken from the 10 normal (nonatopic, nonasthmatic) subjects.
The study was approved by the ethics committees of the Royal Brompton \& Harefield NHS Trust and the London Chest Hospital, and all volunteers gave informed consent prior to participation.

Tissue processing, immunohistochemistry, confocal microscopy

Bronchial mucosal eosinophils. Bronchial mucosal biopsies were fixed in $4 \%$ paraformaldehyde (VWR, Leicester, UK) before being mounted in OCT (optimum cutter) temperature (Bayer UK Ltd., Basingstoke, United Kingdom) and snap-frozen in isopentane (BDH) precooled with liquid nitrogen. Briefly, $6-\mu \mathrm{m}$-thick sections were incubated with a mouse monoclonal antibody against major basic protein (MBP) (BMK 13; in-house) and developed using a modification of the alkaline phosphatase antialkaline phosphatase (APAAP) technique as described previously (33). Appropriate isotype controls were included (Dako Cytomation, Cambridge, United Kingdom). The number of cells per square millimeter was determined by counting whole sections in a blinded fashion at $\times 400$ magnification using an Olympus BH-2 microscope (Olympus, New York, New York, USA).

Reticular basement membrane: tenascin, procollagen III, and lumican. Tissue sections were pretreated with PBS for 30 minutes and incubated overnight at room temperature in a humidified chamber with a mouse antibody against tenascin (Monosan, Uden, The Netherlands), rabbit antibody against procollagen-III (Chemicon International, Harrow, United Kingdom), or lumican (a generous gift of Peter Roughley, Shriner's Hospital for Crippled Children, McGill University, Montreal, Quebec, Canada). After extensive washing, sections were incubated with either a FITC-conjugated goat antimouse $\mathrm{Ab}$ (Dako Ltd.) or FITC-conjugated swine antirabbit $\mathrm{Ab}$ (Dako Ltd.) at a 1:30 dilution for 1 hour. Sections were then incubated with 4',6-diamidino-2-phenylindole (DAPI) (Sigma-Aldrich, Gillingham, United Kingdom) at $1 \mu \mathrm{g} / \mathrm{mL}$ for 5 minutes as a counterstain (to avoid measurement of intracellular protein) and mounted in fluorescent mounting medium (Dako Ltd.). Appropriate isotype controls were included (IgG1, Dako Ltd.). Images were acquired using a Leica TCS SP confocal microscope (Leica Microsystems Ltd., Heidelberg, Germany). The microscope settings were standardized to allow comparison of immunoreactivity intensity among different sections.

Measurements were analyzed using the Scion Image Analysis software package (Scion Corp., Frederick, Maryland, USA). The thickness and density of immunoreactivity in the RBM area was calculated by taking multiple measurements over the length of the biopsy (40-90 measurements) at 20- $\mu \mathrm{m}$ intervals. At each measurement, a line was drawn perpendicular to and across the band of immunoreactivity in the RBM. The image analysis software calculated the length of the line (thickness) and the mean density along the line (pixels per square microns). The values were averaged 

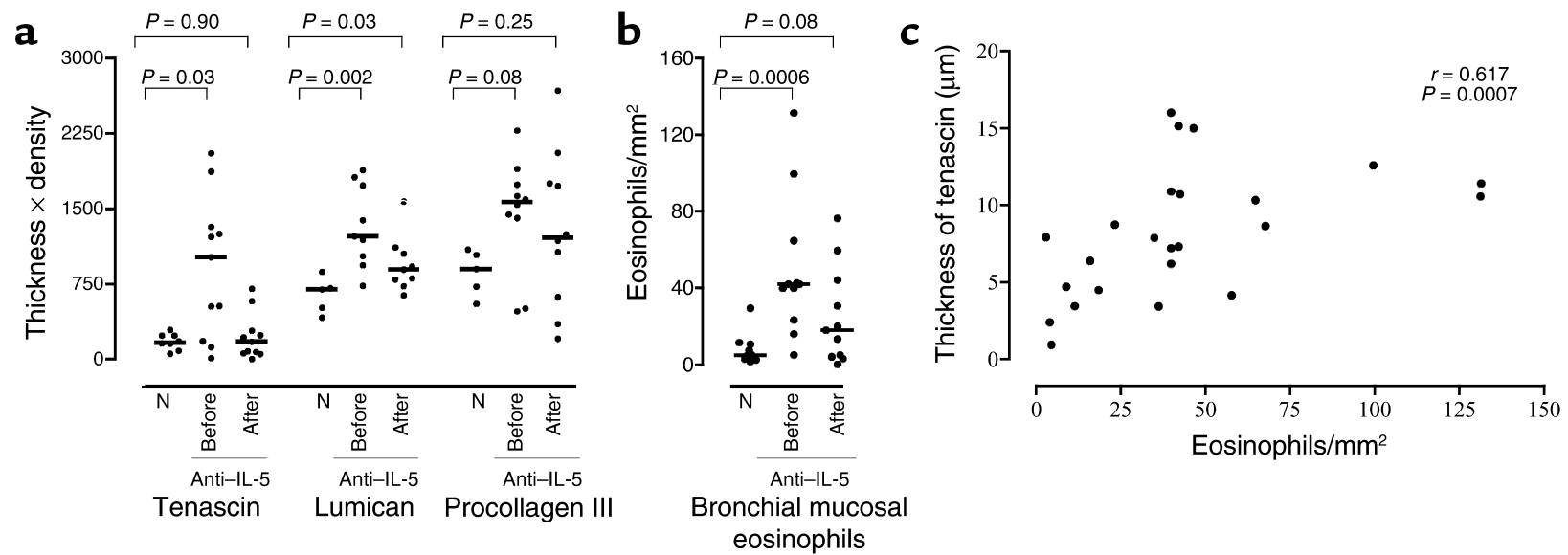

\section{Figure 1}

(a) A comparison of tenascin, lumican, and procollagen III expression in the reticular basement membrane between normal controls $(n=10)$ and asthmatic individuals $(n=11)$ before and after anti-IL-5. $\mathrm{N}$ denotes normal subjects. The crossbars represent the median values. (b) A comparison of the number of $\mathrm{MBP}^{+}$eosinophils in the bronchial mucosa of normal controls and asthmatic subjects at baseline. (c) The correlation between eosinophil numbers and thickness of tenascin in the reticular basement membrane at baseline.

over the whole length of the RBM to give mean thickness and density of immunoreactivity. The product of thickness and density $(t \times d)$ was taken as a measure of expression of the matrix proteins in the RBM. Thickness $\times$ density is a derivative of an equation: mass $=$ density $\times$ volume. Therefore, $t \times d$ is proportional to the mass (or, alternatively, total expression) of matrix protein per unit length of RBM in each biopsy. The intraobserver error for tenascin thickness was $\pm 8.7 \%$, and tenascin density was $\pm 7.3 \%$. This is consistent with previous studies measuring the thickness of tenascin immunoreactivity in the $\operatorname{RBM}(5,34)$.

In situ bybridization and immunohistochemistry. The cDNA fragment encoding human TGF- $\beta 1$ was inserted into a PGEM RNA expression vector (Promega UK Ltd., Southampton, United Kingdom). ${ }^{35}$ S-labeled riboprobes were prepared as previously described (33). TGF- $\beta 1$ mRNA, double immunohistochemistry/in situ hybridization (ISH) was performed as previously described (33). Sections were first stained with antiEG2 (Pharmacia Biotech, Milton Keynes, Bucks, United Kingdom) using the APAAP technique, followed by
ISH (33). For autoradiography, slides were dipped into K-5 emulsion (Ilford Ltd., Basildon, United Kingdom) and exposed at $4{ }^{\circ} \mathrm{C}$ for 3 weeks in complete darkness in a desiccated environment, and the slides were then developed in D-19 developing solution (Eastman Kodak Co., Rochester, New York, USA). Eosinophils were red and TGF- $\beta 1 \mathrm{mRNA}^{+}$signals appeared as silver grains (33). Whole sections were counted in duplicate by investigators unaware of the patients' clinical status, using an eyepiece graticule as previously described (33). Results were expressed as the total number of positive cells per square millimeters of biopsy. The percentage of eosinophils that were TGF- $\beta 1$ $\mathrm{mRNA}^{+}$was also calculated.

Bronchoalveolar lavage fluid TGF- $\beta 1$. BAL fluid was passed through a $50-\mu \mathrm{m}$ filter to remove mucus, centrifuged at $800 \mathrm{~g}$ at $4^{\circ} \mathrm{C}$, and the supernatant was stored at $80^{\circ} \mathrm{C}$ until use. BAL fluid was concentrated 5-30 times at room temperature using Centiplus YM-10 concentrators (Amicon Inc., Beverly, Massachusetts, USA) according to the manufacturer's instructions. TGF- $\beta 1$ levels in the concentrated BAL

Table 1

The effect of mepolizumab on tenascin, lumican, and procollagen III expression

\begin{tabular}{|c|c|c|c|c|c|c|c|c|}
\hline & & \multicolumn{3}{|c|}{ Mepolizumab } & \multicolumn{4}{|c|}{ Placebo } \\
\hline & & Before & After & $P$ value & Before & After & $P$ value & $P$ value $^{\mathrm{A}}$ \\
\hline \multicolumn{2}{|c|}{ Bronchial eosinophils } & $42.0(5.0-131.3)$ & $17.9(4.5-37.3)$ & 0.007 & $36.2(2.9-131.2)$ & $61.7(38.4-86.0)$ & 0.06 & 0.009 \\
\hline Tenascin & $\begin{array}{l}\text { Thickness } \\
\text { Density }\end{array}$ & $\begin{array}{c}10.3(8.1-12.2) \\
96.7(26.3-137.0)\end{array}$ & $\begin{array}{c}5.2(4.7-6.2) \\
34.0(11.7-50.0)\end{array}$ & $\begin{array}{l}0.02 \\
0.01\end{array}$ & $\begin{array}{c}6.2(4.2-8.6) \\
30.5(18.2-42.3)\end{array}$ & $\begin{array}{c}7.8(7.0-9.8) \\
46.3(30.3-76.6)\end{array}$ & $\begin{array}{c}0.19 \\
0.1\end{array}$ & $\begin{array}{l}0.008 \\
0.003\end{array}$ \\
\hline Lumican & $\begin{array}{l}\text { Thickness } \\
\text { Density }\end{array}$ & $\begin{array}{c}10.8(8.9-11.9) \\
135.5(101-147)\end{array}$ & $\begin{array}{c}9.0(8.2-10.4) \\
102.3(89-118)\end{array}$ & $\begin{array}{c}0.3 \\
0.05\end{array}$ & $\begin{array}{c}9.8(9.4-10.5) \\
127.5(95-141)\end{array}$ & $\begin{array}{l}10.1(9.2-10.8) \\
120.3(96-246)\end{array}$ & $\begin{array}{l}1.0 \\
0.98\end{array}$ & $\begin{array}{l}0.16 \\
0.05\end{array}$ \\
\hline Procollagen III & $\begin{array}{l}\text { Thickness } \\
\text { Density }\end{array}$ & $\begin{array}{c}10.4(9.7-11.1) \\
155.8(135-169)\end{array}$ & $\begin{array}{c}10.2(7.9-11.6) \\
140.0(103-160)\end{array}$ & $\begin{array}{c}0.43 \\
0.1\end{array}$ & $\begin{array}{c}9.9(8.5-11.4) \\
151(135.0-179)\end{array}$ & $\begin{array}{c}10.8(9.8-13.2) \\
177.6(151-189.5)\end{array}$ & $\begin{array}{l}0.08 \\
0.28\end{array}$ & $\begin{array}{l}0.22 \\
0.05\end{array}$ \\
\hline
\end{tabular}

Median value (interquartile range). At baseline (before mepolizumab vs before placebo), there were no significant differences in the density or thickness of tenascin, lumican, or procollagen III. ADenotes $P$ value between groups. 
fluid were then determined using a commercial ELISA kit (R \& D Systems Europe Ltd., Abingdon, United Kingdom).

Statistical analysis. Nonparametric statistical methods were used for within-group paired comparisons (Wilcoxon signed rank test) and for between-group comparisons to test the effect of mepolizumab with that of placebo treatment or normal subjects (MannWhitney $U$ test). Correlations were analyzed using Spearman's rank correlation coefficient. A $P$ value of $\leq 0.05$ was considered to be significant.

\section{Results}

Tenascin, lumican, and procollagen III in normal subjects and mild asthmatics. First we sought to confirm that eosinophil infiltration of the bronchial mucosa in asthma was associated with increased deposition of ECM proteins. The total expression (thickness $\times$ density) of tenascin $(P=0.03)$ and lumican $(P=0.002)$ was significantly increased in mild asthmatics when compared with normal subjects, but the changes for procollagen were more variable and did not achieve significance (Figure 1a). Eosinophil numbers were also significantly higher in asthmatics versus normal subjects $(P=0.0006$; Figure $1 \mathrm{~b})$. Immunoreactivity of tenascin and lumican was principally localized to the subepithelial area within the RBM. In the asthmatics, at baseline, there was a positive correlation between the thickness (Figure 1c), density, and total expression of tenascin and the bronchial mucosal eosinophil numbers $(P=0.0007, r=0.617 ; P=0.039, r=0.3661$; $P=0.02$, and $r=0.42$, respectively). These associations were not observed with lumican. There was also no significant correlation between the thickness, density, or total expression of tenascin or lumican and baseline PEFR, $\mathrm{FEV}_{1}$, or histamine $\mathrm{PC}_{20}$.

Effect of anti-IL-5 (mepolizumab) on bronchial mucosal eosinophils and tenascin, lumican, and procollagen III expression in asthma. As previously reported (30), there was a significant decrease in the number of bronchial mucosal eosinophils in asthmatics treated with anti-IL-5 antibody (mepolizumab) compared with placebo $(P=0.009$; Table 1$)$. This was associated with a significant decrease in both the thickness $(P=0.008)$ and density $(P=0.003)$ of tenascin immunoreactivity and in the density of lumican $(P=0.05)$ and procollagen III $(P=0.05)$ immunoreactivity in the RBM when compared with placebo (Table 1 ). The total expression (thickness $\times$ density) is shown in Figure 2. There were significant decreases in tenascin and lumican in the mepolizumab-treated group both within the treated group ( $P=0.01$ and 0.05 , respectively) and when compared with placebo $(P=0.004$ for tenascin and 0.008 for lumican). There was no significant reduction in procollagen III expression in patients treated with anti-IL-5, but there was a significant reduction when compared with placebo $(P=0.007)$, with a trend to increased expression in the placebo group. There was no significant difference between tenascin expression in asthmatics after mepolizumab therapy and the expression of this ECM protein in nonasthmatic. nonatopic controls (Figure 1a).

Figure 3 shows representative photomicrographs of tenascin and lumican immunoreactivity in the bronchial mucosa from subjects before and after treatment with mepolizumab. Examples of procollagen III immunoreactivity are also shown. There was no immunoreactivity observed in sections using appropriate isotype controls for tenascin, lumican, and procollagen.

Effect of anti-IL-5 treatment on TGF $\beta 1$ expression by eosinophils in asthma. At baseline, a median of $86 \%$ of TGF $\beta 1 \mathrm{mRNA}^{+}$cells in the bronchial mucosa of the asthmatic subjects were identified as eosinophils. Following mepolizumab treatment, the numbers of TGF $\beta 1^{+}$eosinophils decreased significantly $(P=0.03)$, compared with placebo (Figure 4a). Similarly, a median of $76 \%$ of eosinophils were TGF- $\beta 1 \mathrm{mRNA}^{+}$at baseline and this decreased significantly, compared with
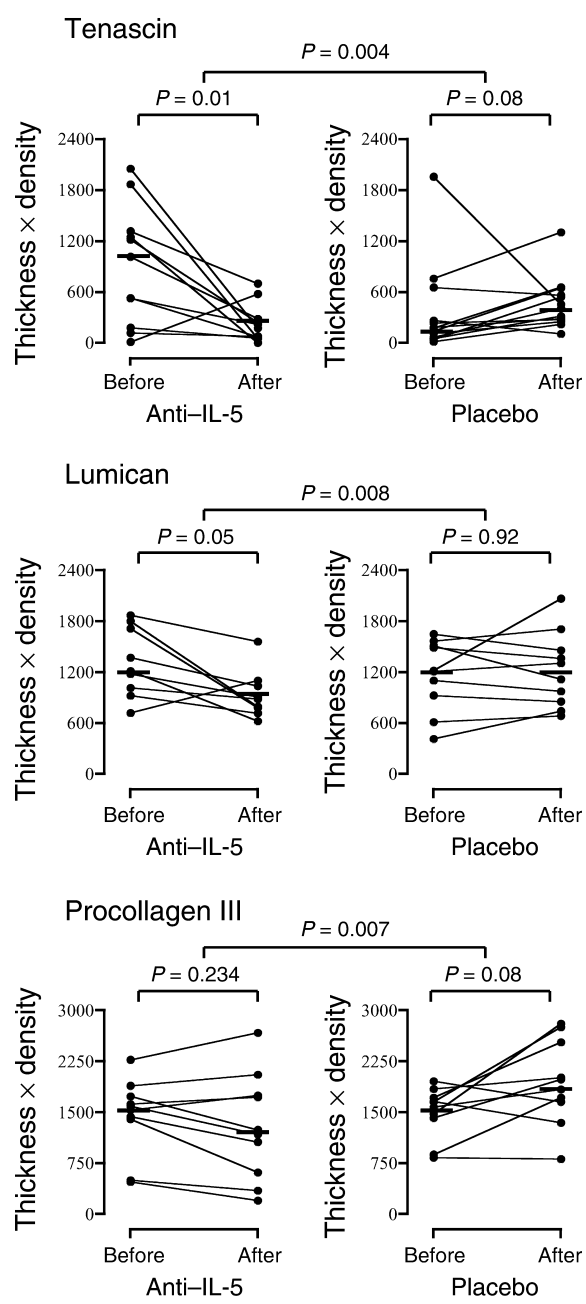

Figure 2

The effect of anti-IL-5 on the total expression (thickness $\times$ density) of tenascin, lumican, and procollagen III in the bronchial subepithelial reticular basement membrane. The crossbars represent the median values. 

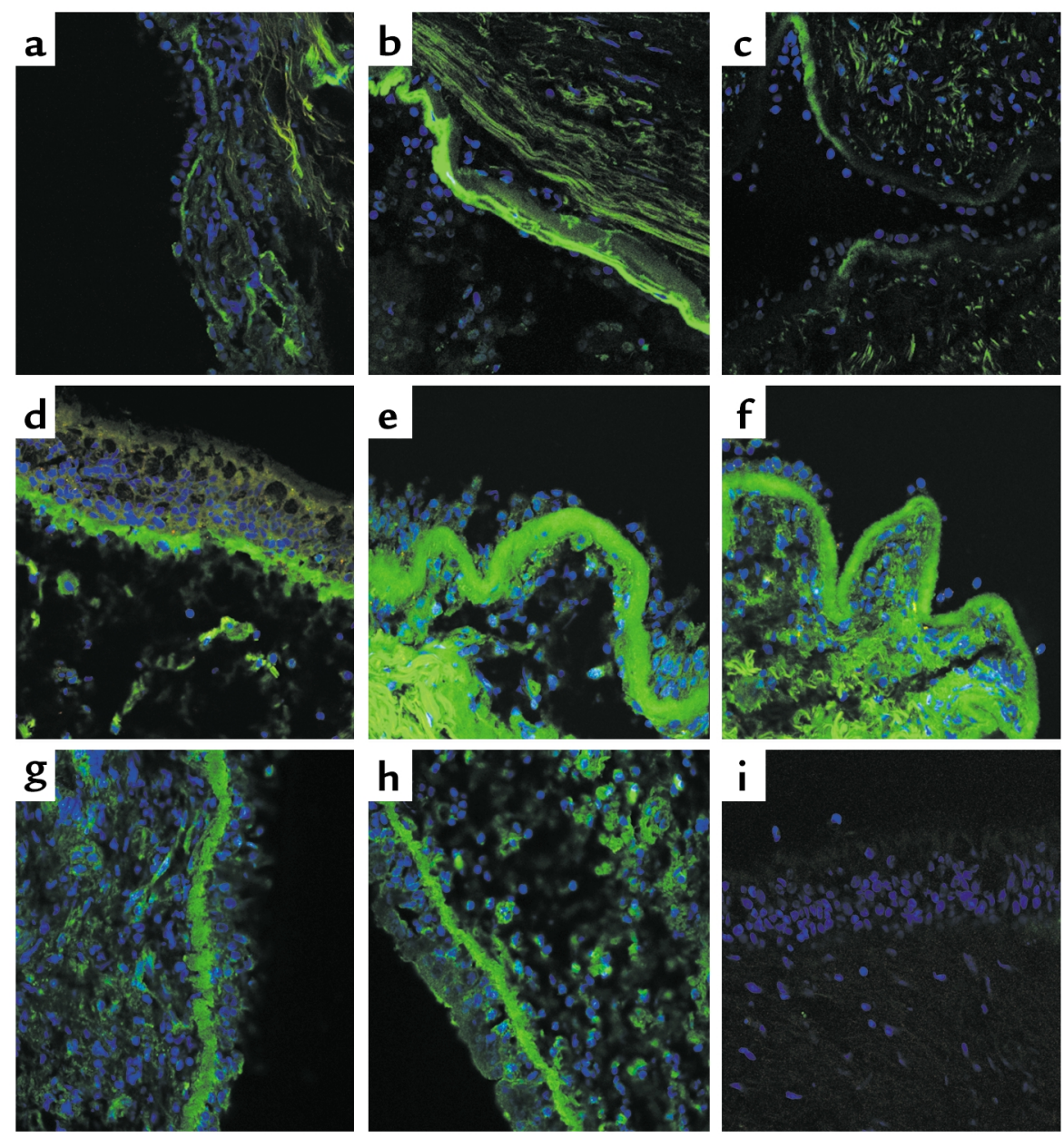

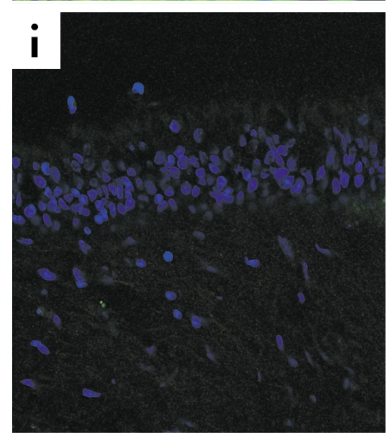

Figure 3

Representative photomicrographs of tenascin immunoreactivity in the reticular basement membrane from a normal subject (a) and from an asthmatic subject pretreatment (b) and posttreatment (c) with anti-IL-5. Lumican immunoreactivity from a normal subject $(\mathbf{d})$ and from pretreatment (e) and posttreatment (f) with anti-IL-5 is also shown. Examples of procollagen III immunoreactivity pretreatment (g) and posttreatment (h) with anti-IL-5 are presented, although the decrease shown was not typical of all subjects. $i$ shows an example of isotype control immunoreactivity. Immunoreactivity of ECM proteins is shown in green. Sections were counterstained with DAPI (blue). placebo, in the mepolizumab-treated group $(P=0.04)$ (Figure 4b). There was also a significant decrease in the concentration of TGF $\beta 1$ in BAL fluid in the mepolizumab-treated group when compared with placebo $(P=0.042$, Figure $4 c)$.

\section{Discussion}

We have shown that specific reduction of eosinophil numbers in the bronchial mucosa in mild asthmatic subjects using an anti-IL-5 monoclonal antibody (mepolizumab) is associated with a significant decrease in the expression of the ECM proteins tenascin and lumican in the reticular basement membrane of the airway mucosa. Furthermore, these changes were associated with significant reductions in TGF- $\beta 1$ expression by airway eosinophils. These data support a novel role for the eosinophil and suggest a link between eosinophilic infiltration and airway remodeling in asthma.

We confirmed previous reports that the thickness of tenascin and lumican within the RBM was significantly greater in asthmatic individuals than in normal subjects $(6,34)$. With tenascin, mepolizumab reduced RBM expression to values observed in nonasthmatic, nonatopic individuals. We also showed that tenascin thickness, density, and total expression correlated with bronchial mucosal eosinophil numbers. Our findings are consistent with those previously reported in animal studies. In an IL-5 gene knockout mouse model of airways remodeling, abrogation of eosinophil infiltration following repeated allergen challenge was associated with an absence of structural changes, including fibronectin production and mucus gland hyperplasia observed in the WT controls (35). In a separate animal model of atopic asthma, prophylactic treatment of ovalbumin-sensitized BALB/c mice with anti-IL-5 significantly reduced the subepithelial fibrosis produced by repeated allergen challenge (36). However, these authors did not report the effects of anti-IL-5 treatment on established fibrosis.

Compared with lumican or procollagen III, there was a particularly close correlation between baseline eosinophils and tenascin expression and a more marked decrease in tenascin expression in response to anti-IL-5 therapy. With procollagen III, mepolizum$\mathrm{ab}$ did not significantly decrease the expression of this ECM protein, although the changes observed were significantly different than with placebo. This suggests a particularly strong association between eosinophils and tenascin deposition, as previously 
shown in allergen-induced tenascin formation in atopic skin (24). It is possible that longer periods of treatment may be required to reverse procollagen and lumican expression to the same degree as that observed with tenascin. Evidence from studies investigating the effect of inhaled corticosteroids on RBM thickness indicates that although short-term treatment is associated with a significant decrease in tenascin thickness in the RBM (5), longer-term studies are required to show a reduction in collagen III thickness $(37,38)$. In the placebo group, there were nonsignificant increases, over the study period, in eosinophils, tenascin, and procollagen, raising a further possibility that these changes reflect the natural history of untreated mild atopic asthma and that anti-IL-5 may have prevented such an increase.

The value for tenascin expression before placebo was lower than before mepolizumab, albeit not significantly lower. Because the treatment groups were otherwise well matched both in terms of clinical and histopathological features and were selected randomly, this difference is most likely the consequence of the relatively small numbers and the large standard deviation of the baseline values for tenascin.

TGF- $\beta 1$ is a potent differentiation factor for the formation of myofibroblasts in vivo and in vitro $(39,40)$ and has been shown to upregulate the expression by fibroblasts of an array of ECM proteins, including tenascin (41). Consistent with previous studies $(42,43)$, we have shown that most of the TGF- $\beta 1 \mathrm{mRNA}^{+}$cells in the submucosa in these mild atopic asthmatics were eosinophils. Selective depletion of eosinophils with anti-IL- 5 significantly reduced the number of TGF- $\beta 1$ $\mathrm{mRNA}^{+}$eosinophils in the bronchial mucosa and decreased TGF- $\beta 1$ concentrations in BAL fluid. In addition, the proportion of cells expressing TGF- $\beta 1 \mathrm{mRNA}$ decreased significantly in the mepolizumab-treated group. This suggests that anti-IL-5 therapy not only decreased the number of eosinophils producing TGF- $\beta 1$, but also reduced the degree of activation of these cells for TGF- $\beta 1$ expression. The fact that the majority of TGF- $\beta 1 \mathrm{mRNA}^{+}$cells were eosinophils, and that levels of TGF- $\beta 1$ in BALF were also reduced supports our hypothesis that eosinophils were an important source of TGF- $\beta 1$ in the bronchial mucosa of asthmatics.

We did not quantify bronchial mucosal myofibroblasts in the present study. The myofibroblast marker $\alpha$-smooth muscle actin is also expressed by a large number of other cells in the bronchial mucosa, and the ultrastructural identification of myofibroblasts using electron microscopy as used by Gizycki and co-workers (44) was beyond the scope of this study. Our previous in vitro work, however, has demonstrated that coculture of eosinophils and fibroblasts is associated with myofibroblast differentiation and the generation of tenascin transcripts and protein, an effect that is inhibited by antibodies directed against TGF- $\beta$ (24). We suggest, therefore, that eosinophil-derived TGF- $\beta 1$ may influence the expression of tenascin and other ECM proteins via the activation of myofibroblasts.
It is also possible that the observed effect of anti-IL-5 on matrix protein expression was mediated by the effect of the drug on IL-5 itself, rather than through the reduction in eosinophil numbers. Although IL-5 has been shown to influence airway smooth muscle contraction (45), it is not known to directly release growth factors from smooth muscle or other cells appropriate to the remodeling changes studied. In addition, the consistent correlation between eosinophil numbers and tenascin thickness before and after mepolizumab therapy makes a direct action of IL-5 unlikely - at least for tenascin. It is equally unlikely that the changes in ECM protein expression could be explained by the action of anti-IL-5 on other cell types in the bronchial mucosa. There were no significant changes in the numbers of other cells in response to anti-IL-5. Although there was a trend towards a
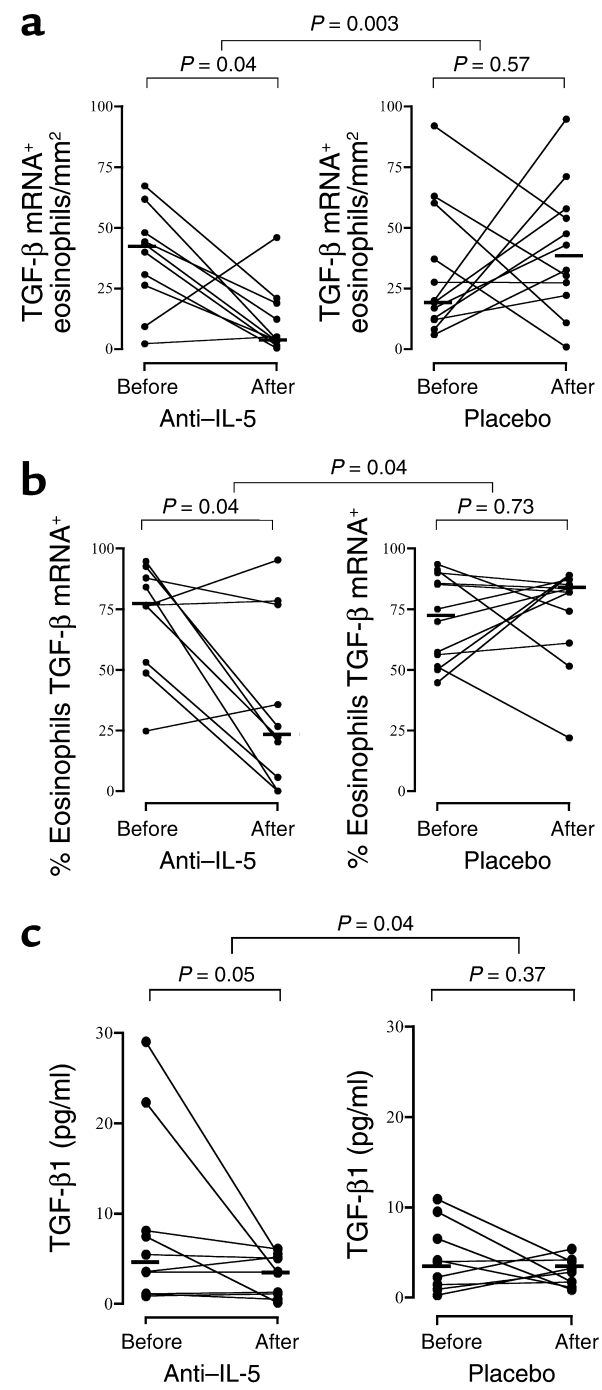

$P=0.04$

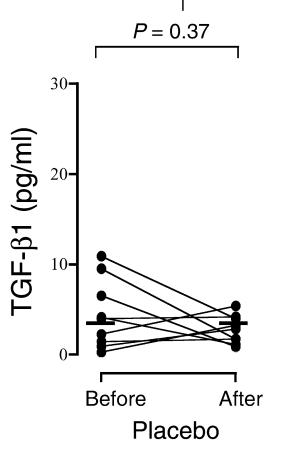

Figure 4

The effect of anti-IL-5 on (a) TGF- $\beta 1$ mRNA $^{+}$eosinophils in the bronchial mucosa, (b) the percentage of eosinophils expressing TGF- $\beta 1 \mathrm{mRNA}$ in the bronchial mucosa, and (c) the concentration of TGF- $\beta 1$ in bronchoalveolar lavage fluid. The crossbars represent the median values. 
reduction in basophil numbers, this did not correlate with changes in ECM protein expression.

The relevance of our findings in terms of asthma pathophysiology is unclear because the effect of airways remodeling on lung function in asthma is uncertain. Deposition of ECM proteins in the airway wall may have a mechanical effect, amplifying the degree of narrowing associated with a given degree of smooth muscle contraction (46). A number of studies have reported a correlation between the thickness of the RBM and airways hyperreactivity (AHR), $\mathrm{FEV}_{1}$, and other markers of asthma severity $(6,34,42,47)$. We found no significant correlation between baseline $\mathrm{PC}_{20}, \mathrm{FEV}_{1}$, and the thickness, density, and expression of tenascin, lumican, or procollagen III. Our subjects were mild asthmatics, and the study was not powered to detect significant correlations in clinical variables such as $\mathrm{FEV}_{1}$ or AHR. Furthermore, although we observed a significant reduction in the expression of tenascin, lumican, and procollagen III in the RBM, we did not measure overall RBM thickness in these biopsies, and it is possible that eosinophil depletion was not associated with so marked a reduction in the expression of other matrix proteins such as fibronectin and types I and $\mathrm{V}$ collagen.

Although anti-IL-5 administration significantly reduced the numbers of tissue eosinophils in the bronchial submucosa, it did not deplete them to the same extent as that reported previously in sputum and blood (28). GM-CSF, IL-3, and eotaxin are also involved in eosinophil homeostasis, and there is evidence that inhibition of these, in conjunction with IL-5 blockade, may be associated with more complete eosinophil depletion from the bronchial mucosa (48, 49). Equally, studies showing the most marked effects of corticosteroids on RBM thickness have tended to be of longer duration, and so sustained eosinophil depletion may be required to achieve a maximal effect (50-52).

In summary, we have shown that the selective reduction of eosinophils in mild asthmatics by anti-IL-5 treatment is associated with a significant decrease in expression of ECM proteins in the airway RBM. Furthermore, this reduction was accompanied by a decrease in TGF- $\beta 1$ expression by airway eosinophils. These data provide strong evidence of a causal association between eosinophils and airway remodeling in mild atopic asthma.

\section{Acknowledgments}

We would like to acknowledge the excellent technical support of Julia Barkans and Farid Benyahia. This study was supported by grants from GlaxoSmithKline and The Wellcome Trust.

1. Bousquet, J., Jeffery, P.K., Busse, W.W., Johnson, M., and Vignola, A.M. 2000. Asthma. From bronchoconstriction to airways inflammation and remodeling. Am. J. Respir. Crit. Care Med. 161:1720-1745.

2. Roche, W.R., Beasley, R., Williams, J.H., and Holgate, S.T. 1989. Subepithelial fibrosis in the bronchi of asthmatics. Lancet. 1:520-524.

3. Wilson, J.W., and Li, X. 1997. The measurement of reticular basement membrane and submucosal collagen in the asthmatic airway. Clin. Exp. Allergy. 27:363-371.

4. Jeffery, P.K., et al. 1992. Effects of treatment on airway inflammation and thickening of basement membrane reticular collagen in asthma. A quantitative light and electron microscopic study. Am. Rev. Respir. Dis. 145:890-899.

5. Laitinen, A., et al. 1997. Tenascin is increased in airway basement membrane of asthmatics and decreased by an inhaled steroid. Am. J. Respir. Crit. Care Med. 156:951-958.

6. Huang, J., Olivenstein, R., Taha, R., Hamid, Q., and Ludwig, M. 1999. Enhanced proteoglycan deposition in the airway wall of atopic asthmatics. Am. J. Respir. Crit. Care Med. 160:725-729.

7. Murphy-Ullrich, J.E. 2001. The de-adhesive activity of matricellular proteins: is intermediate cell adhesion an adaptive state? J. Clin. Invest. 107:785-790.

8. Anwar, A.R., Moqbel, R., Walsh, G.M., Kay, A.B., and Wardlaw, A.J. 1993. Adhesion to fibronectin prolongs eosinophil survival. J. Exp. Med. 177:839-843.

9. Ebina, M., Takahashi, T., Chiba, T., and Motomiya, M. 1993. Cellular hypertrophy and hyperplasia of airway smooth muscles underlying bronchial asthma. A 3-D morphometric study. Am. Rev. Respir. Dis. 148:720-726.

10. Ordonez, C.L., et al. 2001. Mild and moderate asthma is associated with airway goblet cell hyperplasia and abnormalities in mucin gene expression. Am. J. Respir. Crit. Care Med. 163:517-523.

11. Li, X., and Wilson, J.W. 1997. Increased vascularity of the bronchial mucosa in mild asthma. Am. J. Respir. Crit. Care Med. 156:229-233.

12. Wenzel, S.E., et al. 1999. Evidence that severe asthma can be divided pathologically into two inflammatory subtypes with distinct physiologic and clinical characteristics. Am. J. Respir. Crit. Care Med. 160:1001-1008.

13. Todd, R., et al. 1991. The eosinophil as a cellular source of transforming growth factor alpha in healing cutaneous wounds. Am. J. Pathol. 138:1307-1313.

14. Wong, D.T., et al. 1993. Sequential expression of transforming growth factors alpha and beta 1 by eosinophils during cutaneous wound healing in the hamster. Am. J. Pathol. 143:130-142.

15. Noguchi, H., Kephart, G.M., Colby, T.V., and Gleich, G.J. 1992. Tissue eosinophilia and eosinophil degranulation in syndromes associated with fibrosis. Am. J. Pathol. 140:521-528.

16. Wong, D.T., et al. 1990. Human eosinophils express transforming growth factor alpha. J. Exp. Med. 172:673-681.

17. Wong, D.T., et al. 1991. Eosinophils from patients with blood eosinophilia express transforming growth factor beta 1 . Blood. 78:2702-2707.

18. Hoshino, M., Takahashi, M., and Aoike, N. 2001. Expression of vascular endothelial growth factor, basic fibroblast growth factor, and angiogenin immunoreactivity in asthmatic airways and its relationship to angiogenesis. J. Allergy Clin. Immunol. 107:295-301.

19. Okada, S., Kita, H. George, T.J., Gleich, G.J., and Leiferman, K.M. 1997. Migration of eosinophils through basement membrane components in vitro: role of matrix metalloproteinase-9. Am. J. Respir. Cell Mol. Biol. 17:519-528.

20. Levi-Schaffer, F., et al. 1999. Human eosinophils regulate human lungand skin-derived fibroblast properties in vitro: a role for transforming growth factor beta (TGF-beta). Proc. Natl. Acad. Sci. U. S. A. 96:9660-9665.

21. Schmid-Grendelmeier, P., et al. 2002. Eosinophils express functional IL-13 in eosinophilic inflammatory diseases. J. Immunol. 169:1021-1027.

22. Powell, D.W., et al. 1999. Myofibroblasts. I. Paracrine cells important in health and disease. Am. J. Physiol. 277:C1-C9.

23. Paakko, P., Kaarteenaho-Wiik, R., Pollanen, R., and Soini, Y. 2000. Tenascin mRNA expression at the foci of recent injury in usual interstitial pneumonia. Am. J. Respir. Crit. Care Med. 161:967-972.

24. Phipps, S., et al. 2002. The relationship between allergen-induced tissue eosinophilia and markers of repair and remodeling in human atopic skin. J. Immunol. 169:4604-4612.

25. Sanderson, C.J. 1992. Interleukin-5, eosinophils, and disease. Blood. 79:3101-3109.

26. Sehmi, R., et al. 1992. Interleukin-5 selectively enhances the chemotactic response of eosinophils obtained from normal but not eosinophilic subjects. Blood. 79:2952-2959.

27. Rothenberg, M.E., et al. 1989. IL-5-dependent conversion of normodense human eosinophils to the hypodense phenotype uses 3T3 fibroblasts for enhanced viability, accelerated hypodensity, and sustained antibodydependent cytotoxicity. J. Immunol. 143:2311-2316.

28. Leckie, M.J., et al. 2000. Effects of an interleukin-5 blocking monoclonal antibody on eosinophils, airway hyper-responsiveness, and the late asthmatic response. Lancet. 356:2144-2148.

29. Kips, J.C., et al. 2003. The effect of SCH55700, a humanized, anti-hIL5 antibody in severe persistent asthma: a pilot study. Am. J. Respir. Crit. Care Med. 167:1655-1659.

30. Flood-Page, P.T., Menzies-Gow, A.N., Kay, A.B., and Robinson, D.S. 2003. 
Eosinophil's role remains uncertain as anti-interleukin-5 only partially depletes numbers in asthmatic airway. Am. J. Respir. Crit. Care Med. 167:199-204.

31. Liu, L.Y., et al. 2002. Decreased expression of membrane IL-5 receptor alpha on human eosinophils: II. IL-5 down-modulates its receptor via a proteinase-mediated process. J. Immunol. 169:6459-6466.

32. Gregory, G., et al. 2003. Differential regulation of human eosinophil IL-3, IL-5, and GM-CSF receptor-chain expression by cytokines: IL-3, IL-5, and GM-CSF down-regulate IL-5 receptor expression with loss of IL-5 responsiveness, but up-regulate IL-3 receptor expression. J. Immunol. 170:5359-5366.

33. Ying, S., et al. 1999. Eosinophil chemotactic chemokines (eotaxin, eotaxin-2, RANTES, monocyte chemoattractant protein-3 (MCP-3), and $\mathrm{MCP}-4$ ), and C-C chemokine receptor 3 expression in bronchial biopsies from atopic and nonatopic (intrinsic) asthmatics. J. Immunol. 163:6321-6329.

34. Hoshino, M., Nakamura, Y., Sim, J., Shimojo, J., and Isogai, S. 1998. Bronchial subepithelial fibrosis and expression of matrix metalloproteinase-9 in asthmatic airway inflammation. J. Allergy Clin. Immunol. 102:783-788.

35. Trifilieff, A., Fujitani, Y., Coyle, A.J., Kopf, M., and Bertrand, C. 2001. IL-5 deficiency abolishes aspects of airway remodelling in a murine model of lung inflammation. Clin. Exp. Allergy 31:934-942.

36. Blyth, D.I., Wharton, T.F., Pedrick, M.S., Savage, T.J., and Sanjar, S. 2000. Airway subepithelial fibrosis in a murine model of atopic asthma: suppression by dexamethasone or anti-interleukin-5 antibody. Am. J. Respir. Cell Mol. Biol. 23:241-246.

37. Trigg, C.J., et al. 1994. Placebo-controlled immunopathologic study of four months of inhaled corticosteroids in asthma. Am.J. Respir. Crit. Care Med. 150:17-22.

38. Ward, C., et al. 2002. Airway inflammation, basement membrane thickening and bronchial hyperresponsiveness in asthma. Thorax. 57:309-316.

39. Zhang, H.Y., and Phan, S.H. 1999. Inhibition of myofibroblast apoptosis by transforming growth factor beta(1). Am. J. Respir. Cell Mol. Biol. 21:658-665.

40. Desmouliere, A. 1995. Factors influencing myofibroblast differentiation during wound healing and fibrosis. Cell Biol. Int. 19:471-476.

41. Pearson, C.A., Pearson, D., Shibahara, S., Hofsteenge, J., and
Chiquet-Ehrismann, R. 1988. Tenascin: cDNA cloning and induction by TGF-beta. EMBO J. 7:2977-2982.

42. Minshall, E.M., et al. 1997. Eosinophil-associated TGF-beta1 mRNA expression and airways fibrosis in bronchial asthma. Am. J. Respir. Cell Mol. Biol. 17:326-333.

43. Ohno, I., et al. 1996. Transforming growth factor beta 1 (TGF beta 1) gene expression by eosinophils in asthmatic airway inflammation. Am. J. Respir. Cell Mol. Biol. 15:404-409.

44. Gizycki, M.J., Adelroth, E., Rogers, A.V., O’Byrne, P.M., and Jeffery, P.K. 1997. Myofibroblast involvement in the allergen-induced late response in mild atopic asthma. Am. J. Respir. Cell Mol. Biol. 16:664-673.

45. Hakonarson, H., Maskeri, N., Carter, C., Chuang, S., and Grunstein, M.M. 1999. Autocrine interaction between IL-5 and IL-1beta mediates altered responsiveness of atopic asthmatic sensitized airway smooth muscle. J. Clin. Invest. 104:657-667.

46. Wiggs, B.R., Bosken, C., Pare, P.D., James, A., and Hogg, J.C. 1992. A model of airway narrowing in asthma and in chronic obstructive pulmonary disease. Am. Rev. Respir. Dis. 145:1251-1258.

47. Chetta, A., et al. 1997. Airways remodeling is a distinctive feature of asthma and is related to severity of disease. Chest. 111:852-857.

48. Nishinakamura, R., Miyajima, A., Mee, P.J., Tybulewicz, V.L., and Murray, R. 1996. Hematopoiesis in mice lacking the entire granulocytemacrophage colony-stimulating factor/interleukin-3/interleukin-5 functions. Blood. 88:2458-2464.

49. Foster, P.S., et al. 2001. Elemental signals regulating eosinophil accumulation in the lung. Immunol. Rev. 179:173-181.

50. Sont, J.K., et al. 1999. Clinical control and histopathologic outcome of asthma when using airway hyperresponsiveness as an additional guide to long-term treatment. The AMPUL Study Group. Am. J. Respir. Crit. Care Med. 159:1043-1051.

51. Olivieri, D., et al. 1997. Effect of short-term treatment with low-dose inhaled fluticasone propionate on airway inflammation and remodeling in mild asthma: a placebo-controlled study. Am. J. Respir. Crit. Care Med. 155:1864-1871.

52. Hoshino, M., et al. 1998. Inhaled corticosteroid reduced lamina reticularis of the basement membrane by modulation of insulin-like growth factor (IGF)-I expression in bronchial asthma. Clin. Exp. Allergy. 28:568-577. 